\title{
Perfil de crianças e adolescentes vítimas de violência sexual periciados no Instituto Médico Legal em Feira de Santana, Bahia
}

\author{
Wanessa Oliveira Rosario¹; Jeidson Antônio Morais Marques²; Maria Conceição \\ Oliveira Costa ${ }^{3}$; Mona Lisa Cordeiro Asselta da Silva ${ }^{4}$ \\ 1. Bolsista PROBIC/UEFS, Graduando em Enfermagem, Universidade Estadual de Feira de Santana, e-mail: \\ wanessao196@gmail.com \\ 2. Orientador, Docente no Departamento de Saúde, Universidade Estadual de Feira de Santana, e-mail: \\ marques_jam@hotmail.com \\ 3. Coordenadora do Núcleo de Estudos e Pesquisas na Infância e Adolescência, Docente do Departamento de Saúde, \\ Universidade Estadual de Feira de Santana, e-mail: oliveiramco69@gmail.com \\ 4. Participante do Núcleo de Estudos e Pesquisas na Infância e Adolescência, Doutoranda do Departamento de Saúde, \\ Universidade Estadual de Feira de Santana, e-mail: mona.cordeiro@hotmail.com
}

PALAVRAS-CHAVE: violência sexual, criança, adolescente

\section{INTRODUÇÃO}

A violência consiste num grande problema de saúde pública a nível mundial com diferentes manifestações, permeadas por aspectos culturais, sociais e econômicos, que provocam grande impacto na morbidade e mortalidade da população (COSTA, 2012). Entre os grupos mais vulneráveis a sofrer violência, destacam-se as crianças e os adolescentes, podendo ser atribuído muitas vezes à condição de dependência física, emocional e financeira dos genitores ou responsável (SENA et al 2018).

Dentre os principais tipos de violência, especialmente na infância e adolescência destaca-se a violência sexual, que é caracterizada como toda situação onde uma criança ou adolescente é usado por um adulto ou adolescente mais velho, para fins sexuais, podendo ser na forma de abuso ou exploração, com diferentes manifestações (COSTA et al., 2007; SILVA et al., 2016).

As pericias médico-legais de lesão corporal são de grande valor nos casos de abuso sexual, tanto para a comprovação do crime como para a identificação e responsabilização do agressor. O Instituto Médico Legal (IML) é o órgão público de referência para a constatação de qualquer tipo de ofensa à integridade da pessoa humana, encaminhada pela delegacia, ao que compete a produção da prova médico-legal e tipificação do crime. (BEZERRA, 2014; DREZETT et al., 2011; SOUZA, 2009).

Nesse sentido, o levantamento de informações no IML sobre crianças e adolescentes vitimizados sexualmente no município de Feira de Santana em 2014 poderá trazer benefícios para os indivíduos da pesquisa e a comunidade em geral e científica, contribuindo para o conhecimento e a redução dos indicadores de morbimortalidade no município, considerando que há uma escassez de dados que corroborem para criação de medidas intervencionistas para o problema em questão. Este estudo tem como objetivo traçar o perfil de crianças e adolescentes vítimas de violência sexual periciadas no IML de Feira de Santana em 2014.

\section{METODOLOGIA}

Estudo epidemiológico exploratório, transversal, utilizando dados secundários, sobre crianças e adolescentes vítimas de violência sexual periciadas no Instituto Médico Legal de Feira de Santana - Bahia, tendo como população alvo crianças $(\leq 11$ anos), adolescentes (1218 anos), no período de 01 de janeiro a 31 de dezembro de 2014. Os dados foram processados eletronicamente através do programa estatístico Social Package for the Social Sciences SPSS, versão 17.0 for Windows, e apresentados sob a forma de tabelas, buscando associações de variáveis sociodemográficas, relacionadas ao fato e a natureza da violência e variáveis do exame requisitado. 


\section{RESULTADOS E DISCUSSÃO}

Foi verificado em 2014, um total de 192 registros de crianças e adolescentes vítimas de violência sexual, submetidas ao exame pericial conjução carnal/ato libidinoso no município de Feira de Santana - Bahia, na faixa etária entre $01-18$ anos. Verificou-se que as vítimas foram predominantemente do sexo feminino (84,8\%), faixa etária de 10-14 representando 49,5\%; 93,1\% das vítimas eram faiodermas, $100 \%$ solteiros e com escolaridade na faixa do ensino fundamental $79,5 \%$. A profissão foi majoritariamente estudante com $98,4 \%$. A vitimização contra crianças e adolescentes foi predominantemente na modalidade intrafamiliar com $64,6 \%$, o vínculo com o agressor corresponde a maior parte aos conhecidos da família ou vítima com 30,5\%. Quanto ao local da ocorrência, verifica-se que a maioria ocorre na casa da vítima, representando $44,4 \%$. Em relação aos sinais de lesão corporal na vítima, nota-se que dos casos registrados, apenas $2,3 \%$ apresentaram.

Tabela 3 - Distribuição dos casos de violência sexual segundo faixa etária da vítima notificados no Instituto Médico Legal - IML de Feira de Santana, 2014.

\begin{tabular}{|c|c|c|c|c|}
\hline \multirow{2}{*}{ Variáveis } & \multicolumn{4}{|c|}{ Crianças e adolescentes } \\
\hline & \multicolumn{2}{|c|}{ 1-9 anos } & \multicolumn{2}{|c|}{ 10-18 anos } \\
\hline & $\mathbf{N}$ & $\%$ & $\mathbf{N}$ & $\%$ \\
\hline \multicolumn{5}{|l|}{ Sexo da vítima } \\
\hline Masculino & 19 & 23,5 & 10 & 8,3 \\
\hline Feminino & 62 & 76,5 & 110 & 91,7 \\
\hline Total & 81 & 100 & 120 & 100 \\
\hline \multicolumn{5}{|l|}{ Raça/Cor } \\
\hline Faioderma & 68 & 97,1 & 108 & 90,8 \\
\hline Melanoderma & 2 & 2,9 & 10 & 8,4 \\
\hline Leucoderma & - & - & 1 & 0,8 \\
\hline Total & 70 & 100 & 119 & 100 \\
\hline \multicolumn{5}{|l|}{ Estado Civil } \\
\hline Solteiro & 71 & 100 & 116 & 100 \\
\hline Casado(a) & - & - & - & - \\
\hline Total & 71 & 100 & 116 & 100 \\
\hline \multicolumn{5}{|l|}{ Escolaridade } \\
\hline Ensino Fundamental & 20 & 45,5 & 100 & 92,6 \\
\hline Ensino Médio & - & - & 4 & 3,7 \\
\hline Outros 1 & 18 & 40,9 & 4 & 3,7 \\
\hline Não se aplica & 6 & 13,6 & - & 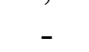 \\
\hline Total & 44 & 100 & 108 & 100 \\
\hline \multicolumn{5}{|l|}{ Profissão } \\
\hline Estudante & 25 & 25 & 98 & 98 \\
\hline Outros $^{2}$ & - & - & 2 & 2 \\
\hline Total & 25 & 100 & 100 & 100 \\
\hline \multicolumn{5}{|l|}{ Vinculo do Agressor } \\
\hline Padrasto & 11 & 36,7 & 8 & 15,4 \\
\hline Pai & 4 & 13,3 & 11 & 21,2 \\
\hline Mãe & - & - & 2 & 3,8 \\
\hline Outros Familiares ${ }^{3}$ & 13 & 43,3 & 4 & 7,7 \\
\hline Conhecidos dos familiares e/ou da vítima ${ }^{4}$ & 2 & 6,7 & 23 & 44,2 \\
\hline Desconhecidos & - & - & 4 & 7,7 \\
\hline Total & 30 & 100 & 52 & 100 \\
\hline Local da ocorrência & & & & \\
\hline
\end{tabular}


Casa da vítima

Casa do agressor

Outros locais ${ }^{5}$

Total

Lesão corporal na vítima

Sim

Não

Total

\begin{tabular}{c|c|c|c}
10 & 55,6 & 6 & 35,3 \\
2 & 11,1 & 3 & 17.6 \\
6 & 33,3 & 8 & 47,1 \\
18 & 100 & 17 & 100 \\
& & & \\
1 & 1,9 & 2 & 2,6 \\
52 & 98,1 & 75 & 97.4 \\
53 & 100 & 77 & 100
\end{tabular}

${ }^{1}$ Outros: Ensino superior incompleto $(\mathrm{n}=1)$; Alfabetizado $(\mathrm{n}=4)$; Não alfabetizado $(\mathrm{n}=17)$

${ }^{2}$ Outras profissões: Doméstica $(\mathrm{n}=1)$; Lavradeira $(\mathrm{n}=1)$

${ }^{3}$ Outros familiares: Irmão $(n=1)$; Primo $(n=5)$; Tia $(n=1)$; Tio $(n=7)$; Avô $(n=3)$

${ }^{4}$ Conhecidos dos familiares e/ou da vítima: Conhecido $(n=1)$; Colegas $(n=1)$; Namorado $(n=15)$; Marido $(n=1)$; Cuidadora ( $\mathrm{n}=1)$; Vizinho (n=4); Ex-namorado $(\mathrm{n}=1)$; Amigo do primo $(\mathrm{n}=1)$

${ }^{5}$ Outros Locais: Casa da avó (n=3); Casa da madrinha $(\mathrm{n}=1)$; Casa do amigo $(\mathrm{n}=1)$; Casa do avô $(\mathrm{n}=1)$; Casa do vizinho $(\mathrm{n}=2)$; Motel $(\mathrm{n}=14)$; Casa do parceiro $(\mathrm{n}=1)$; Casa da tia $(\mathrm{n}=1)$; Trabalho $(\mathrm{n}=1)$

A predominância do gênero feminino demonstrado nos resultados deste estudo pode estar relacionada à fragilidade feminina nas relações de gênero ou decorrente da condição de superior força física do sexo masculino, tornando as crianças e adolescentes do sexo feminino alvos preferenciais dos agressores (SENA et al., 2018; MARTINS; JORGE, 2010).

Observa-se um número acentuado de casos na idade entre 10 a 14 anos corroborando com o estudo de Moreira et al (2017) e Alves et al (2017), essa faixa etária corresponde a parte da adolescência. $\mathrm{O}$ autor ainda acrescenta que essa fase é mais acometida devido à autonomia, deslocamentos, participação social e integração a grupos de jovens, contribuindo dessa forma para maior vulnerabilidade a situações de violência (MOREIRA et al., 2017).

Em relação a raça/cor, nota-se que a maior parte era faioderma (pardo) e corrobora com o estudo realizado por Silva et al. (2018). A predominância da escolaridade no período do ensino fundamental corrobora com o estudo realizado por Moreira et al. (2017), que também demonstrou que maior parte das crianças e adolescentes estão nesse nível de escolaridade.

O vínculo com o agressor, que se caracterizou como conhecido da família ou da vítima pode ser explicado pela facilidade de acesso ao ambiente da criança e adolescente, bem como da proximidade com a família, levando consequentemente a maior vulnerabilidade para ocorrência do fato (MOREIRA et al., 2017; SILVA et al., 2018).

Quanto ao local de ocorrência, teve destaque a casa da vítima, o que corrobora com o estudo feito por Souto et al (2018), Garbin et al (2016) e também com o estudo realizado por Martins e Jorge 2010. A residência como local de violência, revela que os agressores são próximos, sendo parte da família ou alguém que tenha acesso a casa (SOUTO et al., 2018).

A violência sexual na modalidade intrafamiliar teve destaque nesse estudo e corrobora com Dias et al (2018). Neste tipo de modalidade, a dificuldade existente em relatar o ocorrido é o receio, principalmente por parte da própria criança, que tem medo de punições (SOUTO et al., 2018).

Estudo realizado por Martins e Jorge (2010) demonstrou que a maioria dos casos de violência sexual $(90,3 \%)$ ocasionou lesão corporal, divergindo do presente estudo. Segundo o mesmo autor, a qualidade da informação pode prejudicar quanto á determinação da presença da lesão.

\section{CONSIDERAÇÕES FINAIS}

Diante dos danos e agravos que a violência sexual determina entre crianças e adolescentes, este tipo de abuso constitui-se um problema de saúde pública, sendo necessárias ações intersetoriais, visto que se trata de um problema multifatorial. Portanto, espera-se, com os achados deste estudo, além de incentivar a notificação, maior atenção seja dada a esse 
assunto, promovendo a divulgação de informações que possam subsidiar a elaboração de políticas públicas e promover a visibilidade dessa temática para as famílias e pessoas próximas da vítima, a fim de conscientiza-las a respeito de um perigoso e oculto problema que pode estar dentro do ambiente doméstico da vítima.

\section{REFERÊNCIAS}

ALVES, J. M.; VIDAL, E. C. F.; FONSECA, F. L. A.; et al. Notificação da violência contra crianças e adolescentes por profissionais de saúde. Rev Fac Ciênc Méd Sorocaba, v. 19, n. 1, p. 26-32. 2017.

BEZERRA, F. L. Perfil da violência contra mulheres analisadas junto ao NUMOL/CG no ano de 2012. 2014. 29f. Trabalho de Conclusão de Curso (Graduação em Direito)Universidade Estadual da Paraíba, Campina Grande, 2014.

COSTA, M. C. O. Diga não à violência sexual contra crianças e adolescentes no seu município. Feira de Santana - BA: UEFS. 2012.

COSTA, M. C. O,; CARVALHO, R. C,; BARBARA, J. F. R. S. et al. O perfil da violência contra crianças e adolescentes, segundo registros de Conselhos Tutelares: vítimas, agressores e manifestações de violência. Ciência \& Saúde Coletiva, v. 12, n. 5,p.1129-1141. 2007.

DIAS, G. C.; COSTA, M. C. O.; MUSSE, J. O. Violação Sexual de Crianças e Adolescentes: perfil dos casos notificados nos Conselhos Tutelares em município de grande porte da Bahia.

Rev. Saúde Col. UEFS, Feira de Santana, v. 8, p. 23-29. 2018.

DREZETT, J.; JUNQUEIRA, L.; TARDELLI, R. et al. Influência do exame médico legal na responsabilização do autor da violência sexual contra adolescentes. Revista Brasileira de Crescimento e Desenvolvimento Humano, v. 21, n. 2, p. 189-197. 2011.

GARBIN, C. A. S.; GOMES, A. M. P.; GATTO, R. C. J.; et al. Um Estudo Transversal Sobre Cinco Anos de Denúncia Sobre Violência Contra Crianças e Adolescentes em Araçatuba São Paulo. J Health Sci, v.18, n. 4, p. 273-277. 2016.

MARTINS, C. B. G.; JORGE, M. H. P. Abuso sexual na infância e adolescência: perfil das vítimas e agressores em município do sul do brasil. Texto Contexto Enferm, Florianópolis, v. 19, n. 2, p. 246-55. 2010.

MOREIRA, K. F. A.; OLIVEIRA, D. M.; OLIVEIRA C. A. B.; et al. Perfil das crianças e adolescentes vítimas de violência. Rev enferm UFPE, Recife, v. 11, n. 11, p. 4410-7. 2017. SENA, C. A.; SILVA, M. A.; NETO, G. H. F. Incidência de violência sexual em crianças e adolescentes em Recife/Pernambuco no biênio 2012- 2013. Ciência \& Saúde Coletiva, v. 23, n. 5, p. 1591-1599, 2018.

SILVA, L. M. P.; SOUSA, T. D. A.; CARDOSO, M. D.; et al. Violência perpetrada contra crianças e adolescentes. Rev enferm UFPE on line., Recife, v. 12, n. 6, p. 1696-1704. 2018. SILVA, C. B. et al. Caracterização do perfil da violência sexual em crianças e adolescentes no Rio Grande do Sul. Revista de Epidemiologia e Controle de Infecção, Santa Cruz do Sul, out. 2016. ISSN 2238-3360. Disponível em:

<https://online.unisc.br/seer/index.php/epidemiologia/article/view/8223>. Acesso em: $20 \mathrm{de}$ jun. 2017.

SOUTO, D. F.; ZANIN, L.; AMBROSANO, G. M. B.; FLÓRIO, F. M. Violência contra crianças e adolescentes: perfil e tendências decorrentes da Lei n ${ }^{\circ}$ 13.010. Rev Bras Enferm, v. 71, n. 3, p. 1313-1323. 2018. 